\title{
Environmental Conservation of Endangered Manipur Brow- Antlered Deer (Rucervus eldii eldii) For Sustainable Population Management under Captive Environment in National Zoological Park, Delhi, India
}

\author{
Pratyansha Singh ${ }^{1}$, Amarjeet Kaur ${ }^{2}$ and Manoj Kumar ${ }^{3}$ \\ ${ }^{1}$ Ph.D. Scholar in University School of Environment Management, Guru Gobind Singh Indraprastha University, \\ Sector 16C, Dwarka, Delhi 110078, India (email: jeni241990@ gmail.com) \\ ${ }^{2}$ Professor in University School of Environment Management \& Director in Centre for Disaster Management \\ Studies, Guru Gobind Singh Indraprastha University, Sector 16C, Dwarka, Delhi 110078, India (corresponding \\ author's phone: 09810479919; email: amarjeet_ip@yahoo.com) \\ ${ }^{3}$ Scientist and In-charge in Geomatics Centre, Forest Informatics Division, Forest Research Institute, Dehradun \\ 248006, India (email: manojfri@gmail.com)
}

\begin{abstract}
This study of population serves as an important role in terms of management and conservation of Manipur Brow-antlered deer (Rucervus eldii eldii) in National Zoological Park, Delhi in order to assess its current population as well as historical population data and the factors affecting them. Evaluation has been done by taking current (April 2016 to August 2017) and historical (April 1962 to March 2016) population data which evaluated stock position, births, deaths and disposals trends. Causal factors behind births and deaths as well as the percentage distribution of various causes of death have also been defined. Month wise distribution of births and deaths demonstrated their prevalence in different seasons viz. Pre-rut, Rut and Post-rut seasons. Recommendations have been made regarding future population management practices for sustainable harvest of Manipur Brow-antlered deer by creating naturalistic and enriched environment in zoo following guidelines of Central Zoo Authority of India.
\end{abstract}

Keywords: Manipur Brow-antlered deer, National Zoological Park (NZP), Population management.

\section{Introduction}

India, the efforts toward ex-situ conservation have received considerable attention after the enactment of Indian Wildlife (Protection) Act, 1972. Zoological parks and gardens have been recognized and strengthened for the ex-situ conservation of endangered flora and fauna. National Zoological Park (NZP), Delhi is one of such center where the protection of Endangered Manipur Brow- antlered deer is being carried out. Zoos play very important role in maintaining good animal husbandry that supports healthy populations of animals [1]. Captive breeding programs in zoos serve as important tools for conservation and preservation of endangered species [2]. For achieving sustainability in zoos, intensive population management practices are necessarily required [3]. The purpose of population management is to ensure that healthy and viable populations of species of our choice are available, for the foreseeable future. Reference [4] noted that animals in captivity have the benefits of veterinary care, lack of predators, and a regular supply of food. But on the other hand, captive animals also suffer injury from exhibits [5] and poor adaptation to captivity [6]-[7]. Also, the inbreeding depression can decrease survival and reproduction of small captive populations [8].The population inside an ex-situ environment should be made to increase as rapidly as possible by improved population management and planning so that they would be able to serve as security against catastrophe and also for reintroduction programs [9]. 
Management of population is also needed to maintain a long-term viable population and to preserve genetic diversity [8]. Captive breeding programs are an important tool for the conservation of endangered species. These programs are commonly managed using pedigrees containing information about the history of each and every individual's family, such as breeding pairs and parentage.

The Manipur Brow-antlered deer (Rucervus eldii eldii) is recognized as "Endangered" under the IUCN Red List of Threatened Species [10] which is having the highest list of protection under the Schedule I of the Indian Wildlife (Protection) Act, 1972. Central Zoo Authority (CZA) of India listed Manipur Brow-antlered deer under Conservation Breeding Program to restore their population in several zoological gardens including NZP, Delhi. At present, there are fourteen Indian zoological gardens which are breeding 211 Manipur Brow-antlered deer in its captivity.

The NZP is a 188.62 acres Zoo situated near the Old Fort in Delhi, India. It started rearing Manipur Browantlered Deer with the stock position of two individual in the year 1962. It is currently breeding the largest stock in India i.e., 53 individual Manipur Brow-antlered Deer in an enclosure of 8006 square meters showing better management and reproductive success. Apart from holding a good stock, it is showing fluctuation in the population trend line of Manipur Brow-antlered Deer due to several reasons and factors. Identification and assessment of those variables behind population fluctuation would help to draw conclusions regarding existing gaps in Conservation Breeding Program. This study has made an attempt to recommend better management strategies regarding perpetuation of a viable population of the Manipur Brow-antlered Deer in NZP, Delhi.

\section{Methodology}

The methodology adopted for study of population management included primary (April 2016 to August 2017) and secondary data (April 1962 to March 2016) collection for population parameters and factors governing its growth. The secondary data included Zoo inventory records regarding sex, date of birth, death, causal factors of death, date of acquisition and disposal. During the primary data collection, observations were made in the NZP, Delhi for the above mentioned parameters.

The collected data was analyzed using quantitative methods and the results were shown in the form of graphs, charts and summarized tables indicating population trend analysis, causal factors and seasonal occurrence of births and deaths. Month wise seasonal distribution has been done during Pre-rut (October to January), Rut (February to May) and Post-rut (June to September) seasons on the basis of observation during breeding period from April 2016 to August 2017. The variation in the stock position has been done on the basis of number of births, deaths, acquisition and disposal over a period of time. These four factors were considered for the calculation of population trend.

\section{Results}

\subsection{Population Trend Analysis}

The population of Manipur brow-antlered deer in NZP reported 307 births, 174 deaths, 81 disposals and zero acquisition for the period of April 1962 to August 2017.

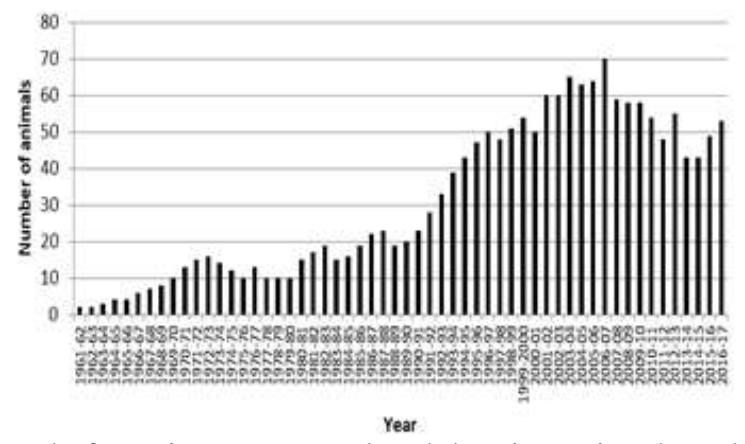

Fig. 1: showing population trend of Manipur Brow-antlered deer in National Zoological Park, Delhi (1962-2017) 
Fig. 1 explained the recorded stock position for the period of April 1962 to March 2017 which subsequently increased in general with varying rates up to the peak year 2007. After this period, a trend of declining stock position can be observed up to the year 2016-17. NZP holding a surplus stock position of 23 in the year 199091showed an increase of 53 individuals in the year 2016-17which is greater than the required/targeted number in stock i.e., 20as per the recommendations of Central Zoo Authority, India Guidelines. In the period of April August 2017, the stock positionwas52 with the reported death of only one individual.

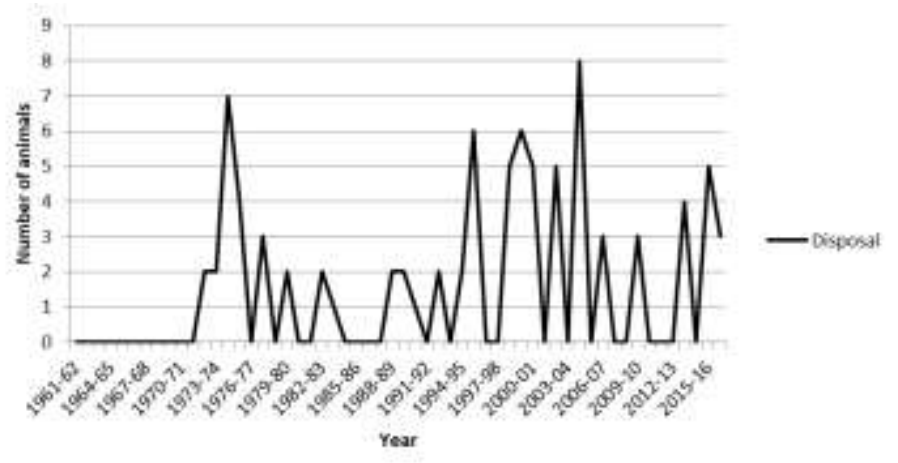

Fig. 2: showing disposal (animal exchange) trends of Manipur Brow-antlered deer in National Zoological Park, Delhi (1962-2017)

Fig. 2 shows disposals /transfer of animals done from NZP to the different zoos in India. Rise and fall was seen in the graph with highest disposals i.e., eight in the year 2004-05. No disposal was recorded in April August 2017.

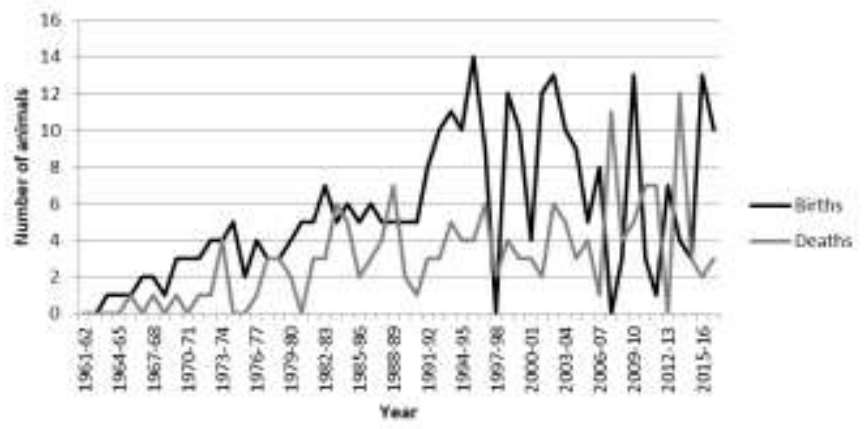

Fig. 3: showing birth and death trends of Manipur Brow-antlered deer in National Zoological Park, Delhi (1962-2017)

Increasing trend in the population growth was observed as a result of increase in the number of births during observation period and the maximum number of birth was up to a peak level of 14 births during the year 199495 (Fig. 3). The number of birth shows an increasing trend during the observation period. This increasing trend followed a sudden decline with zero birth in the year 1997-98. This trend of sharp rise and fall has continued up to the end of the observed period till 2016-17.

The graph representing the number of death showed a fluctuating trend. A sudden increase in the number of death (11) was reported in 2007-08. The occurrence of death was maximum (12) in the year 2013-14 which was then followed by declining trend till 2016-2017. During the period of April - August 2017, only one death was recorded.

\subsection{Causal factors for Births and Deaths}

During April 1962 to August 2017, 307 births have been reported which indicates good management practices for upkeep of Manipur Brow-antlered deer population in NZP. There were various causal factors responsible for the 174 deaths which affected the stock position. 


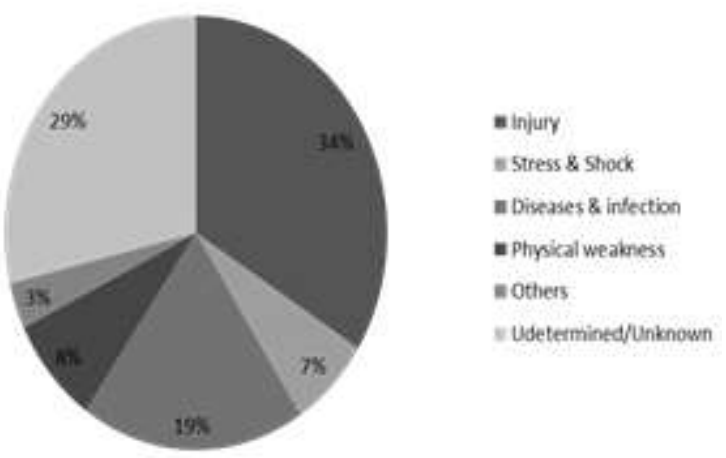

Fig. 4: showing percentage distribution of death causes of Manipur Brow-antlered deer in National Zoological Park, Delhi (1962-2017)

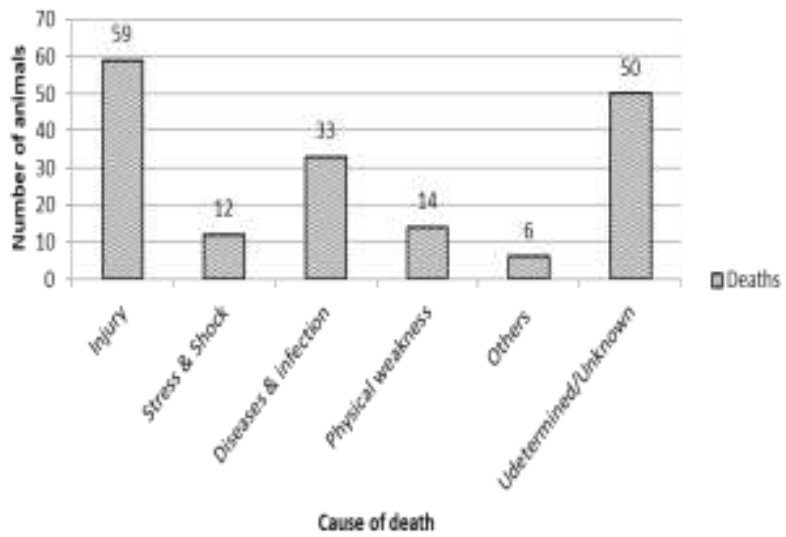

Fig. 5: showing average death causes of Manipur Brow-antlered deer in National Zoological Park, Delhi (1962-2017)

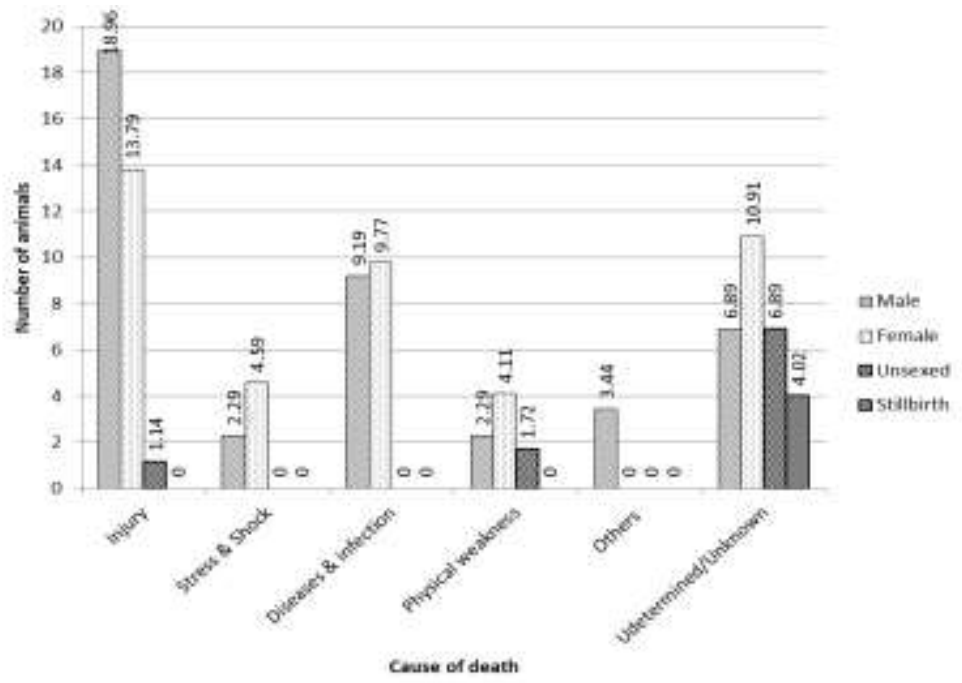

Fig. 6: showing percentage distribution of death causes in different sex classes of Manipur Brow-antlered deer in National Zoological Park, Delhi (1962-2017)

Among the various causes of deaths (Fig. 4 \& 5), Injury has shown the highest percentage of the causes behind the death of Manipur Brow-antlered deer, followed by the other causal factors. Injury due to infighting (especially male aggression towards males and females), self-destructive behaviour and internal injury caused approximately $34 \%$ of total deaths i.e., 59 deaths (Fig. 5) showed highest depletion of stock position over time. Sex wise distribution of death causes has been represented in the Fig. 6. Maximum deaths were recorded in the 
pre-rut and rut due to infighting injury; and more in males than females. Others include self-destructive behaviour and internal injury. All these types of Injuries were the major causes for population depletion in captivity. Infant mortality $(6.89 \%)$ and stillbirths $(4.02 \%)$ were significantly reported under the category of Undetermined deaths. Diseases \& infection showed 19\% of total deaths i.e., 33 deaths, followed by other causes.

\subsection{Seasonal Occurrence of Births and Deaths}

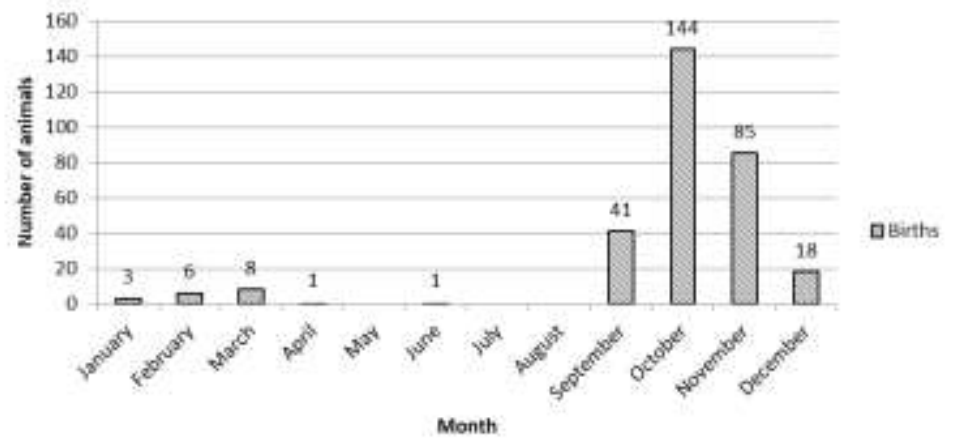

Fig. 7 showing month wise distribution of births of Manipur Brow-antlered deer in National Zoological Park, Delhi (1962-2017)

Fig. 7 indicates that female deer starts to give birth from the month of September, with its prominence in Pre-rut seasons (October to December). Maximum number of births (144) occurred in the month of October. Some births were also reported other than favourable months of pre-rut i.e., in February, March, April and June. Occurrence of deaths can be seen in all seasons (months) with maximum number of deaths (30) recorded in the month of November (post-rut season) and the main cause behind these deaths was stress and shock in case of two male and seven female. Female deaths occurred due to parturition stress or postpartum stress. Also, two cases of stillbirths were also recorded in the same month. Distribution of causes of death, according to different seasons (month wise), has been presented in the Fig. 8.

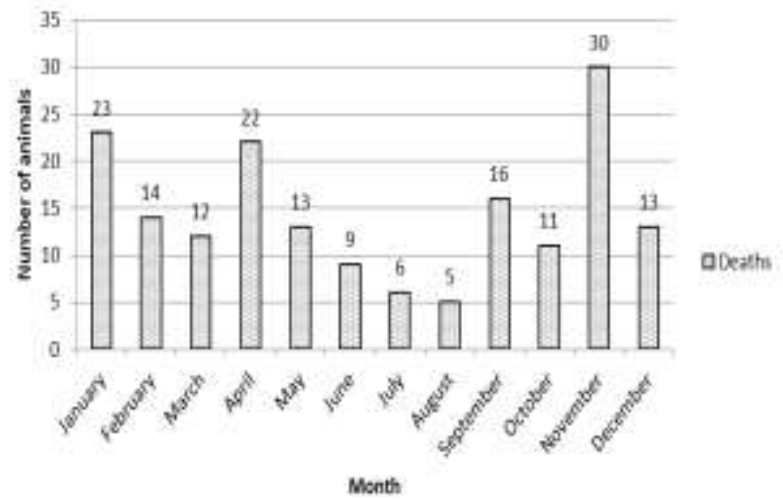

Fig. 8 showing month wise distribution of deaths of Manipur Brow-antlered deer in National Zoological Park, Delhi (19622017)

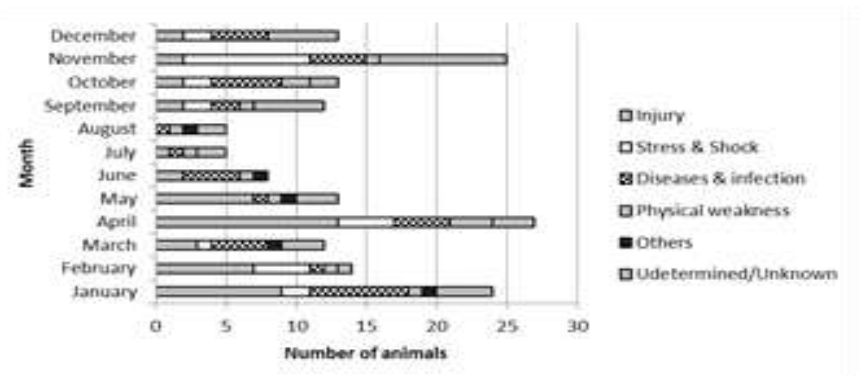

Fig. 9: showing month wise distribution of death causes of Manipur Brow-antlered deer in National Zoological Park, Delhi (1962-2017) 
Fig. 9 showed that the different causes of deaths showed their combined effect in all the seasons. Deaths due to maximum number of cause were reported in the month of April i.e. in the pre-rut season showing injury, stress \& shock, diseases \& infection, physical weakness and undetermined/ unknown reasons. Least contribution of death causes was seen in the month of July due to injury, diseases \& infection and undetermined/ unknown reasons. Injury has been reported in the maximum percentage in all seasons except August with maximum number of deaths in pre-rut and rut seasons (January- May), followed by diseases \& infection and others (for percentage distribution, Fig. 5).

\section{Discussion}

Assessment of a population's historical and current pattern of growth is important in determining its potential for future growth [8]. The present study depicts important trends of different phases in a population's growth. The increasing trend of population denotes increment in the stock position which further indicates that there were more births, less deaths and fewer disposals. The decreasing trend showed declination of stock position indicating fewer births, more deaths and more acquisition in that particular year. The variations in the stock position show its linkages with the number of births and deaths in a given period of time. More number of births (297) and less number of deaths (170) have been reported showing good care, upkeep and better housing facilities. The maximum stock position was recorded in the year 2007 with eight births, only one death and no acquisition throughout the year. So, for a better stock position, successful births with less number of deaths (especially infant mortality) should be maintained in captivity. The stock position also indicated the surplus population of Manipur Brow-antlered deer (more than required/targeted number i.e., 5 male: 15 female as per the guidelines of CZA). Control of excessive breeding and transfer of excessive numbers should be done in order to maintain more stocks across different zoos (CZA).

Maximum numbers of births (14) which were recorded in months of October, November, December and January in the year 1995-1996 during pre- rut seasons indicates successful conception and parturition in favourable conditions under captivity. Maximum numbers of deaths (12) were recorded in the months of April, September, October and January in the year 2013-14. Causes behind these deaths were infighting injury during pre-rut and rut season, undermined/ unknown death, Dystocia and post-partum stress during post-rut season. Thus, Population growth in captivity depends upon the number of fertile male and female on oestrus, adequate space inside enclosure, successful conception, healthy pregnancy, care and upkeep of pregnant females [9].

This study also revealed that the percentage of births and deaths show their significant relationship with breeding seasons. Births were reported highest in the Pre-rut season indicating healthy conceived female, nutritional feed, successful pregnancy and parturition. Prevalent cause of deaths was reported in pre-rut and post rut seasons due to infighting (male aggression) injury [9]. Injury was witnessed as one of the major death causes during all the seasons; followed by undetermined deaths, diseases, infections and others. Death cases can be reduced by marking and removal of aggressive males from one particular enclosure to another one [11]. Active exchange of animals and artificial insemination is suggested to increase heterozygosity and to decrease infant mortality in a captive population [9]. Evaluation regarding distribution of death causes in different seasons is required to frame the preventive measures and to develop weather gear arrangements other than the existing management practices of NZP.

Disease prevention is considered as an important factor in terms of conservation of rare and endangered species [12]-[13]-[14]-[15]-[16]. Various types of diseases \&infection were found to be major causes behind population depletion. These can be controlled by disease prevention and eradication of existing disease [17]. A thorough knowledge of particular type of diseases and infection with high frequencies will help to develop strategic preventive measures for future population. Deaths of individuals have been recorded in each month (1962-2015) and each month shows number of deaths due to different causal factors. Season specific death causes should be evaluated and studied for the development of mitigation measures against each and every death [9]. 
This study also revealed that for more accurate population study and analysis, marking of individual should be done every year. This can help to recognize each individual for the maintenance of pedigree chart and scrupulous records of births, transfers, and causes of deaths including infant mortalities; other factors can also be determined by marking so that correct demographic and genetic information about the herd can be extracted [8].This information serves as a necessity for maintaining and managing heterozygosity in captive population. It will also help to determine the root cause of infant mortality under conservation breeding program. Exchange of animals or genetic materials is required to be done before the next breeding seasons and should immediately be implemented by the zoo authorities. Hand rearing and artificial insemination for overcoming infant mortalities and female infertility problems should be done [9]. This would be able to draw more precise strategies for demographic and genetic management of Manipur Brow-antlered deer population in National Zoological Park, Delhi.

\section{Recommendations}

The following recommendations have been made to suggest better conservation management practices for captive Manipur Brow-antlered deer in NZP, Delhi as per CZA Guidelines [18]:

1. More naturalistic and enriched environment in zoo should be created inside enclosure to provide a feel of enriched natural environment/habitat. Such enriched habitat should be developed in order to accommodate the physical, physiological and social requirements of the deer. Specific measures in this concern such as development of wallowing area are suggested to prevent infighting and physical injury during the breeding season.

2. Camera surveillance and Tagging or marking of animal should be done on a regular basis to continuously monitor and record the population and behavior of the animals. These techniques could help to understand the reasons of undetermined / unknown deaths as well as to identify the individuals showing their important role in progeny.

3. An immediate step should be taken for the translocation of the stock once the surplus population is achieved.

4. Active exchange of animals along with genetic material (semen or embryos) among the various zoos and acquisition of animals from wild should be practiced in order to maintain heterozygosity in the population.

These recommendations will help to fill the existing management gaps in conservation breeding program of Manipur Brow-antlered deer population in captivity. This will eventually help to develop a healthy, heterozygous and viable stock population in NZP and all similar ex-situ conservation plans.

\section{Conclusion}

The study of population serves as an important tool in terms of management and conservation of Manipur Brow-antlered deer in captivity. Knowledge about stock position, births, deaths, acquisition and disposal number provide valuable information about increasing and decreasing trend of population. Evaluating the reasons behind fluctuation in births and deaths trend would help to assess the gap in existing zoo management. A prudent population management is needed as per the available adequate capacity of zoo. The captive animals should be managed in a more sustainable manner by suitable conservation efforts and planning (Lacy 2013).

\section{Acknowledgment}

The authors are highly grateful to Smt. Renu Singh, Director and Shri Amitabh Agnihotri, Ex-Director of the National Zoological Park, Delhi for providing population data from the zoo records and all other assistance during the population study. We would also like to thank Shri Riaz Ahmed Khan, Curator, Dr. Manoj Kumar, Biological Assistant, Shri Bhupen Roka, Zoo Ranger, Dr. Abhijeet Bhawal, Veterinary Officer and Zookeepers for their guidance and support during this study. 


\section{References}

[1] D. M. Powell, and J. V. Watters, "The Evolution of the Animal Welfare Movement in US Zoos and Aquariums, "Der Zoologische Garten, vol. 86, no. (1-6), pp.219-234, 2017.

[2] B.Jimenez-Mena, K. Schad, N.Hanna, and R.C. Lacy, "Pedigree analysis for the genetic management of group-living species," Ecology and evolution, vol. 6, no. 10, pp. 3067- 3078, Apr. 2016.

[3] R.C. Lacy, "Achieving true sustainability of zoo Populations," Zoo Biology, vol. 32, no. 1, pp.19-26, July 2012.

[4] J. Courtenay, and G. Santow, Mortality of wild and captive chimpanzees, " Folia Primatologica, vol. 52, no. 3-4, pp.167- 177, Aug. 1989.

[5] K.M. Leong, S.P. Terrell, and A. Savage, "Causes of mortality in captive cotton-top tamarins (Saguinus oedipus), " Zoo Biology, vol. 23, pp.127-137, Apr. 2004.

[6] L. Karstad, and L. Sileo, "Causes of death in captive wild waterfowl in the Kortright Waterfowl Park 1967-1970," Journal of Wildlife Diseases, vol. 7, pp. 236-241, Oct. 1971.

[7] A. Gozalo, and E. Montoya, "Mortality causes of the moustached tamarin (Saguinus mystax) in captivity, Journal of Medical Primatology, vol. 21, pp. 35-38, Jan. 1992.

[8] J. D. Ballou, C.Lees, L. J. Faust, S. Long, C. Lynch, L. Bingaman Lackey, and T.J. Foose,"Demographic and genetic management of captive Populations (Wild mammals in captivity: principles and techniques for zoo management, eds. D.G. Kleiman, K.V.Thompson, and C.K. Baer)," in Science, $2^{\text {nd }}$ ed., University of Chicago Press, 2010, pp. 219-252.

[9] PHVA, "Population \& Habitat Viability Assessment for Manipur brow-antlered deer, " A Collaborative Workshop Chamarajendra Zoological Gardens, Mysore Forest Department of Manipur, Indian Zoo Directors' Association, Zoo Outreach Organisation, CBSG, India Captive Breeding Specialist Group, SSC, IUCN, 80pp, 1992.

[10] T.N.E Gray, S.M. Brook, W.J. McShea, S. Mahood, M.K. Ranjitsingh, A. Miyunt, S.A. Hussain, and R. Timmins, "Rucervus eldii. The IUCN Red List of Threatened Species 2015: " e.T4265A22166803.Retrieved from http://dx.doi.org/10.2305/IUCN.UK.2015-2.RLTS.T4265A22166803.en., 2015.

[11] A. Barat, and G. Poyyamoli, " Captive breeding and zoo policy in India - lessons from Arignar Anna Zoological Park, ”Zoos' Print Journal, vol. 15, no. 1, pp. 177-183, Jan. 2000.

[12] G. P. Scott, D. M. Burn, and L. J. Hansen, "The dolphin dieoff: long term effects and recovery of the populati (Ocean's 88: proceedings), " in Institute of Electrical and Electronics Engineers, New York, vol. 3 ,no. 88, ch. 25858, 1988, pp. 819-823,

[13] M. Hutchins, T. Foose, and U.S. Seal, "The role of veterinary medicine in endangered species conservation," Journal of Zoo and Wildlife Medicine, vol. 22, no. 3, pp. 277-281, Sept. 1991.

[14] A. M. Lyles, and A.P. Dobson, “ Infectious disease and intensive management: population dynamics, threatened hosts, and their parasites, " Journal of zoo and wildlife medicine, pp. 315-326, Sept. 1993.

[15] L. Munson, and R.A. Cook, “ Monitoring, investigation, and surveillance of diseases in captive wildlife. " Journal of zoo and wildlife medicine, pp. 281-290, Sept. 1993

[16] F. M. D. Gulland, "The impact of infectious diseases on wild animal populations: a review ( Ecology of infectious diseases in natural populations, eds. B. T. Grenfell, A. P. Dobson)" in Mathematics, Cambridge University Press, Cambridge, 1995, pp. 20-51.

[17] G. Wobeser, "Disease management strategies for Wildlife," Revue Scientifiqueet Technique-Office international des epizooties, vol 21, no. 1, pp.159-178, 2002.

[18] "Central Zoo Authority of India, Statutory body under the Ministry of Environment, Forest and Climate Change (Government of India); "http://cza.nic.in/guidelines.html, n.d. (no date). 